\title{
Role for D-Serine within the Ventral Tegmental Area in the Development of Cocaine's Sensitization
}

\author{
Emilio Fernandez-Espejo*,', Susana Ramiro-Fuentes', Manuel Portavella² and Rocio Moreno-Paublete' \\ 'Departamento de Fisiologia Medica, Universidad de Sevilla, Sevilla, Spain; ${ }^{2}$ Departamento de Psicologia Experimental, Universidad de Sevilla, \\ Sevilla, Spain
}

\begin{abstract}
Repeated exposure to cocaine results in motor sensitization that, in the ventral tegmental area (VTA), is associated to enhanced glutamate release, which in turn leads to enhanced calcium levels in dopaminergic neurons. Calcium influx activates calcium-calmodulindependent protein kinases such as CaMKII. D-Serine could participate on these effects, and the objective was to discern the role of VTA D-serine after a sensitizing regimen of cocaine $(10 \mathrm{mg} / \mathrm{kg}$ daily), and to discern consequent expression changes in CaMKII and its activated form. For this purpose, D-serine, sodium benzoate (inhibitor of D-amino acid oxidase, the degradating enzyme of D-serine), and 7-chlorokynurenate (inhibitor of the glycine site of NMDA receptors) were injected into the VTA (in either the induction or expression phase of sensitization), and activation state of CaMKII was assessed through blotting. The findings indicated that intra-VTA administration of D-serine $(5 \mathrm{mM})$ and sodium benzoate $(100$ and $200 \mu \mathrm{g} / \mu \mathrm{l})$ during the induction phase (not expression) reliably augmented the expression of behavioral sensitization to cocaine, providing evidence that D-serine in the VTA participates in the initiation of motor sensitization to this psychostimulant drug. Intra-VTA infusions of D-serine, sodium benzoate and 7-chlorokynurenate did not elicit a motor effect of their own. Confirming the important role of NMDA receptors and their activation at the glycine site, the employment of 7-chlorokynurenate ( 2 and $5 \mu \mathrm{g} / \mu \mathrm{l}$ ) led to blocking of the development of sensitization to cocaine. CaMKII within the VTA was found to participate in D-serine's effects because this kinase, that is activated after repeated cocaine, was further activated after co-treatment with D-serine or sodium benzoate. Besides CaMKII activity was otherwise reduced by 7-chlorokynurenate.
\end{abstract}

Neuropsychopharmacology (2008) 33, 995-1003; doi: I0.1038/sj.npp. I 301495; published online 4 July 2007

Keywords: VTA; cocaine; D-serine; sensitization; sodium benzoate; 7-chlorokynurenate; CaMKII

\section{INTRODUCTION}

Repeated exposure to cocaine results in motor sensitization, which is manifested through an enhancement of the motoractivating effects of cocaine, and is considered as a model of neural plasticity (Wise, 2000; Nestler, 2001; Kelley, 2004). The neuroadaptations mediating sensitization could underlie some of the behavioral changes associated with chronic psychostimulant abuse (Robinson and Berridge, 1993). Chronic cocaine exposure produces biochemical adaptations in specific brain regions thought to mediate activating properties of cocaine (Koob and Bloom, 1988; Nestler, 2001). The mesolimbic system is the most important system involved in these adaptations, which comprises dopaminergic neurons in the ventral tegmental area (VTA) and their projections to the limbic forebrain such as the nucleus accumbens (Wise and Rompre, 1989; Nestler, 2001). In the VTA, the development of sensitization to psychostimulants is associated to enhanced glutamate release, which in turn

\footnotetext{
*Correspondence: Dr E Fernandez-Espejo, Departamento de Fisiologia Medica y Biofisica, Universidad de Sevilla, Av. Sanchez Pizjuan 4, E-4 1009 Sevilla, Spain, Tel: + 34 954556584, Fax: + 34954551769 , E-mail: efespejo@us.es

Received 3 October 2006; revised 29 May 2007; accepted 31 May 2007
}

leads to enhanced calcium levels in dopaminergic neurons. Glutamatergic terminals from the laterodorsal tegmentum are involved in these effects. Glutamatergic neurotransmission is further enhanced through upregulation of AMPA and NMDA receptors following repeated cocaine. AMPA and NMDA become more permeable to calcium after cocaine's administration (Licata and Pierce, 2003).

D-Serine could participate on these effects, because this mediator substance, that is present in the VTA, is important in modulating NMDA receptor activity in the central nervous system (Schell et al, 1995; Haydon, 2001; Boehning and Snyder, 2003), and D-serine is known to bind NMDA receptors (glycine site) facilitating their activation (Yang et al, 2003). In the VTA, astrocytes are the main source of Dserine, even though a role for VTA neurons cannot be discarded because recently it has been shown that neurons also synthesize and release D-serine, mostly in the cortex and cerebellum (Kartvelishvily et al, 2006). Besides glutamate induces release of $\mathrm{D}$-serine from both astrocytes and neurons, and in turn astrocytes are also known to influence glutamate levels in the biophase (through the glutamate-cystine antiporter). In this context, sensitizationrelated changes in the VTA have been compared to longterm potentiation (LTP) in the hippocampus, and astrocytes play a key role in long-term synaptic plasticity, providing 
D-serine that facilitates activation of NMDA receptors in developing cerebellum and hippocampus (Schell et al, 1997; Yang et al, 2003). A single injection of cocaine is known to induce LTP of AMPA receptor-mediated current in dopaminergic neurons in the VTA (Ungless et al, 2001). Facilitation of glutamate receptors leads to enhanced calcium influx in dopamine VTA neurons, and calcium and calcium-mediated second messenger systems play an important role in the expression of behavioral sensitization (Karler et al, 1991; Reimer and Martin-Iverson, 1994; Licata et al, 2004). Intracellular calcium binds calmodulin to become an active complex that can regulate many enzymes such as the calcium-calmodulin-dependent protein kinase II (CaMKII) which seems to play a pivotal role (Nakamura et al, 2000), because intra-VTA infusions of KN-93 (CaMKII inhibitor) prevent the development of sensitization (Licata et al, 2004). Moreover, behavioral sensitization to cocaine is attenuated in CaMKII knockout mice (Licata and Pierce, 2003). CaMKII has been proposed as a candidate molecule for long-term storage of information mediating plasticity changes underlying sensitization (Licata and Pierce, 2003).

The role of D-serine within the VTA in the development of cocaine's sensitization and activation of CaMKII is not known. The objectives of the present study were to discern the role of $\mathrm{D}$-serine in the VTA after a sensitizing regimen of cocaine (in both induction and expression phases), and to discern consequent expression changes in CaMKII and its activated form. For this purpose, D-serine (agonist of the glycine site of NMDA receptors), sodium benzoate (inhibitor of D-amino acid oxidase (DAAO), the degradating enzyme of D-serine), and 7-chlorokynurenate (antagonist of the glycine site of NMDA receptors) have been injected into the VTA, and activation state of CaMKII in the VTA has been assessed through blotting.

\section{MATERIALS AND METHODS}

\section{Animals}

Adult male Wistar rats from the breeding colony of the Faculty of Medicine of the University of Seville, Spain, were used. Laboratory temperature was kept at $22 \pm 1^{\circ} \mathrm{C}$, and a 12-h light-dark cycle (lights on at 0800 hours) was maintained throughout the experiment. Food (lab chow) and water were available ad libitum.

\section{Drug and Compounds}

Cocaine hydrochloride was purchased from Sigma-Aldrich (St Louis), and dissolved in $0.9 \%$ saline. Sodium benzoate was purchased from Sigma-Aldrich, and dissolved in saline. D-serine was purchased from RBI (USA), and dissolved in saline. 7-chlorokynurenate was purchased from SigmaAldrich, and it was dissolved in DMSO and before use dose was adjusted in 10\% DMSO\% and 90\% water. Corresponding vehicle was used for treatments.

\section{Surgery and Intrabrain Injections}

Before surgery, rats were anesthetized $(50 \mathrm{mg} / \mathrm{kg}$ ketamine, $10 \mathrm{mg} / \mathrm{kg}$ xylazine), given prophilactic peniciline and placed in a stereotaxic apparatus. A hole was drilled over the injection site, and a 22-gauge stainless-steel guide cannula (Small Parts, Miami) was aimed $2 \mathrm{~mm}$ above the corresponding infusion site: VTA, $A P=-5.2, L=0$, and $V=-6.2 \mathrm{~mm} v s$ bregma (Paxinos and Watson, 2005). The guide cannula was fastened to the skull with stainless-steel screws and dental cement, and was fitted with a 30 -gauge stainless-steel obturator, protruding $2 \mathrm{~mm}$ out of the tip of the guide cannula (Small Parts). Rats were allowed 1 week for recovery before injections. Intrabrain injections were performed in the home cage after removing the obturator cannula, that was replaced by a 30-gauge stainless-steel internal cannula connected to a Hamilton syringe and a delivery pump (Stoelting, Germany). Solutions were slowly injected over $5 \mathrm{~min}$, and afterwards the internal cannula was carefully removed and the obturator cannula was replaced.

\section{Behavior Experiments}

Motor activity (distance traveled, $\mathrm{m}$ ) was recorded over $2 \mathrm{~h}$ in locomotion cages $(45 \times 45 \mathrm{~cm})$ by using the automatized Smart system (Panlab, Spain). Two days before the first cocaine injection, rats were placed on the environment during $2 \mathrm{~h}$ each day without treatment, to avoid the effects of novelty on motor activity (habituation days). Besides, on each treatment day the rats were habituated to the cages for $1 \mathrm{~h}$. Following this habituation period, injectors were lowered into the VTA to administer the microinjections. Ten minutes after intra-VTA infusions, rats received an injection of cocaine $(10 \mathrm{mg} / \mathrm{kg} \mathrm{IP})$ and their motor behavior was monitored during $2 \mathrm{~h}$ post-injection (every 20-min period of time was also monitored). Cocaine was injected daily on days 1-5 (induction phase of sensitization) as well as on days 12 and 20 (expression days of sensitization). Intra-VTA injections (volume, $0.7 \mu \mathrm{l}$ ) of sodium benzoate $(0,100$ and $200 \mu \mathrm{g} / \mu \mathrm{l})$, D-serine $(0,1$, and $5 \mathrm{mM})$, vehicle, or 7 -chlorokynurenate $(0,2$, and $5 \mu \mathrm{g} / \mu \mathrm{l})$ and its vehicle were performed during either the induction or expression phases of sensitization. Regarding infusions during induction, intra-VTA injections were performed every day $10 \mathrm{~min}$ before systemic cocaine as explained. Regarding expression, other rats were subjected to intrabrain injections on days 12 and 20 (expression phase), $10 \mathrm{~min}$ before the challenge cocaine injection. Each experimental group encompassed 7-8 rats. The motor effects of intra-VTA D-serine, sodium benzoate, and 7-chlorokynurenate alone were also studied in different groups of rats $(n=7$ each). These animals were pretreated with sodium benzoate, D-serine, 7-chlorokynurenate, or vehicle before a systemic injection of saline rather than cocaine, during days $1-5$ and days 12 and 20, following a similar protocol.

\section{Histology}

Following completion of the locomotor sensitization studies, rats were given an overdose of chloral hydrate $(450 \mathrm{mg} / \mathrm{kg}$ IP) and perfused intracardially with $0.9 \%$ saline followed by $20 \%$ paraformaldehyde. The brain was then removed and coronal sections $(50 \mu \mathrm{m})$ were taken at the level of the VTA with a vibratome. The sections were mounted on gelatin-coated slides and stained with cresyl violet (Sigma-Aldrich). Cannula placements were mapped onto a stereotaxic atlas (Paxinos and Watson, 2005), and confirmed to be in the VTA. 


\section{Western Blotting}

For this study, other rats ( $n=7$ each group) with cannulae aimed at the VTA were subjected to three systemic injections regime in the home cage: (i) single saline or cocaine injection, (ii) five daily systemic injections preceded each $(10 \mathrm{~min}$ before) by intra-VTA D-serine $(5 \mathrm{mM})$, IP sodium benzoate $(200 \mu \mathrm{g} / \mu \mathrm{l}), 7$-chlorokynurenate $(5 \mu \mathrm{g} / \mu \mathrm{l})$ or corresponding vehicle. Cocaine was always injected at $10 \mathrm{mg} / \mathrm{kg}$ IP. Twentyfour hours after the last systemic injection, rats were killed by decapitation and brains were removed, and cooled in ice-cold physiological buffer. The VTA region was obtained by careful dissection of the region under microscope observation. Brain samples were lysated in $10 \%$ glycerol, $137 \mathrm{mM} \mathrm{NaCl}$, and $20 \mathrm{mM}$ Tris- $\mathrm{HCl} \mathrm{pH}, 7.5$, containing peptidases $(1 \mu \mathrm{g} / \mathrm{ml}$ aproteinin and leupeptin, $1 \mathrm{mM}$ PMSF). Protein levels were quantified by using the Bradford method. Samples were boiled and aliquots containing $25 \mu \mathrm{g}$ of protein each were subjected to SDS/polyacrylamide gel electrophoresis. Proteins were transferred electrophoretically to PVDF membranes, which were then blocked with $2 \%$ nonfat dry milk in TTBS pH 7.5 (5 M NaCl, 2\% $1 \mathrm{M}$ Tris- $\mathrm{HCl}, 0.05 \%$ Tween-20). Immunolabeling was conducted for CaMKII with rabbit polyclonal antibody $\left(\mathrm{Ca}^{2+} /\right.$ calmodulin kinase II, $1: 1000$, Cell Signaling, Beverly, MA, USA), anti-CaMKII(P) with mouse monoclonal antibody (anti-Ca ${ }^{2+} /$ calmodulin kinase II $\alpha$ subunit $\mathrm{pThr}^{286} ; 1: 2000$, Calbiochem, Merck, Darmstadt, Germany), and $\alpha$-tubulin (control protein) with mouse monoclonal anti- $\alpha$-tubulin antibody (Santa Cruz Technologies, Santa Cruz, USA). Primary antibodies were detected with peroxidase-linked secondary antibodies, and with enhanced chemiluminescence (Amersham, GE HealthCare, Piscataway, $\mathrm{NJ}$ ), and autoradiography. Band densities of resulting autoradiograms were quantified by using the Scion Image for PC (NIH).

\section{Statistical Analysis}

For behavioral study, a two-way ANOVA (treatment, between factor; day, within factor) was employed, followed by the Tukey's test. The Student's $t$-test (unpaired samples) was used for comparing two groups the same treatment day, as well as for comparing percentage changes in distance traveled. Time-course data were analyzed with two-way ANOVA (treatment, between factor; time point, within factor), followed by the Student's $t$-test for comparing groups at the same time point. When variance was not homogeneous, data were logarithmically $(\log [x])$ transformed before analysis. Blotting band densities after acute treatment were compared by the Student's $t$-test, and after repeated treatment by one-way ANOVA followed by the Student's $t$-test (independent samples) for comparing groups. Experiments were performed according the animal care guidelines of the European Communities Council (86/609/EEC).

\section{RESULTS}

\section{Location of Microinjection Sites in the VTA}

Figure 1 illustrates cannula tip locations in the VTA, as well as representative pictures of coronal sections stained with the Nissl technique. Inspection of brain tissue revealed evidence of a localized lesion, and gliosis at the site of injection, although surrounding tissue was generally intact.

\section{Repeated Intra-VTA Infusion of the D-Serine or Sodium Benzoate during the Induction Phase Enhances the Development of Sensitization to Cocaine}

Two-way ANOVA indicated a significant treatment $\times$ day interaction effect $(\mathrm{F}(12,144)=5.1, p<0.01)$ on motor activity
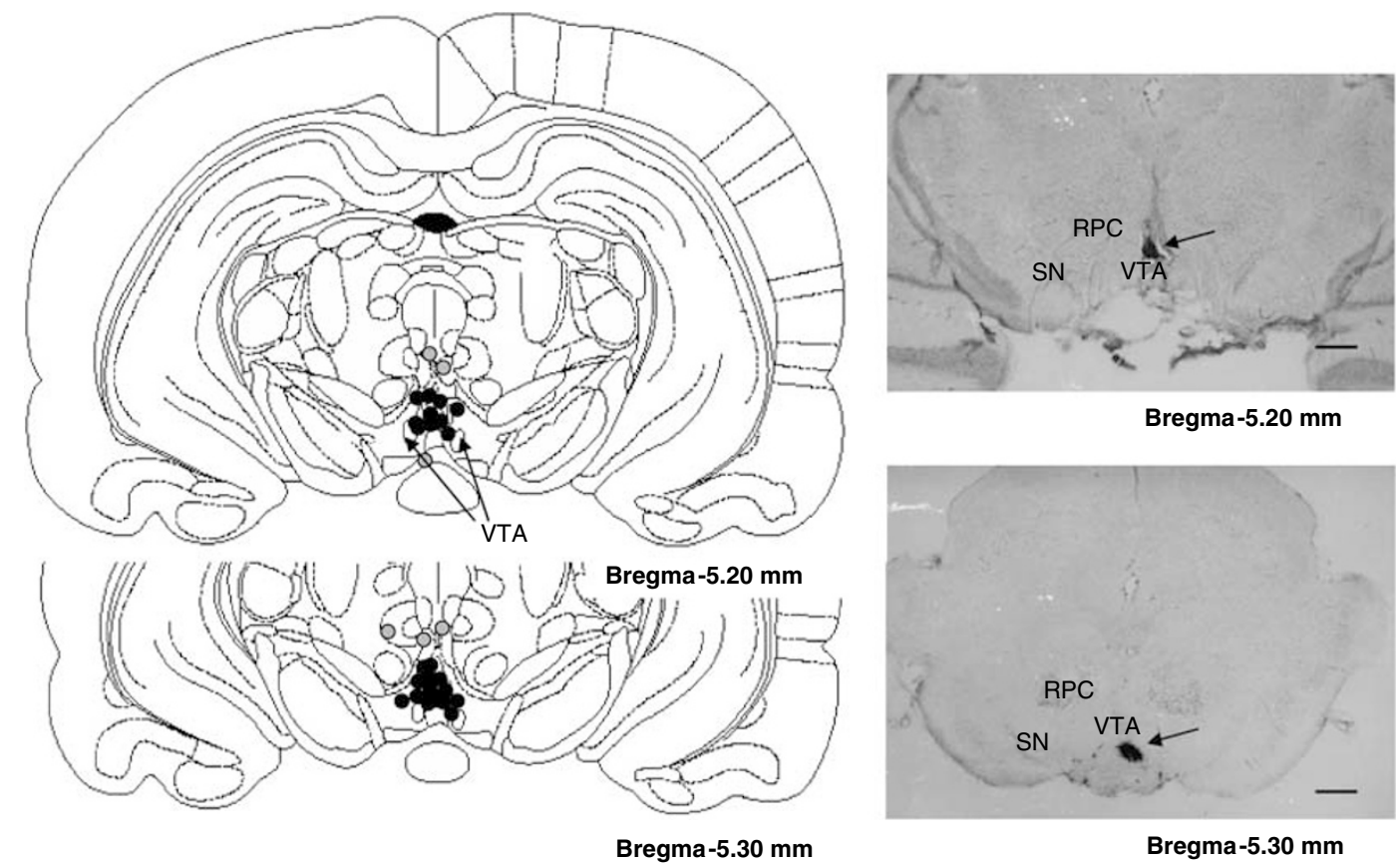

Figure I Locations of infusions into the VTA and representative pictures of sites of injections (Nissl technique). Rats with cannula tip locations outside the VTA (gray dots) were discarded for statistical analysis. Plates are taken from Paxinos and Watson (2005). Abbreviations: RPC, red nucleus parvicellular; $\mathrm{SN}$, substantia nigra; VTA, ventral tegmental area. Bar: I mm. 
after infusions of D-serine during induction. All rats treated with systemic cocaine and intra-VTA vehicle saline or D-serine presented a significant enhancement of motor activity on days $5(p<0.05), 12$ and $20(p<0.01) v s$ day 1 , but this effect was significantly higher on days 12 and 20 in those animals treated with $5 \mathrm{mM}$ D-serine, as shown in Figure 2. Thus, percentage increase in distance traveled on days 12 and 20 relative to day 1 was significantly higher in rats pretreated with $5 \mathrm{mM}$ D-serine (day 12, $166.5 \pm 21 \%$ and day 20, $173.8 \pm 22 \%$, $p<0.05$ ) than vehicle (day $12,99.5 \pm 10 \%$ and day 20 , $103.1 \pm 11 \%$ ) and $\mathrm{D}$-serine $1 \mathrm{mM}$ (day $12,102 \pm 10 \%$; day 20 , $103.7 \pm 12 \%)$. As for time-course study, distance traveled values after cocaine (every 20-min period of time) were quantified on days 1 and 20 of treatment, as shown in Figure 1. Two-way ANOVA indicated a significant interaction effect $(\mathrm{F}(25,240)=76.6, p<0.01)$. Post hoc analysis revealed that distance traveled was enhanced from 0 to $60 \mathrm{~min}$ in all groups on day $20 v$ day $1(p<0.01)$, and this value was significantly higher on day 20 in rats treated with $5 \mathrm{mM}$ D-serine $v s$ the other groups at the same day $(p<0.05)$ from 0 to $40 \mathrm{~min}$ postinjection. Hence intra-VTA D-serine was able to enhance cocaine's sensitizing effects.

Regarding sodium benzoate infusions, two-way ANOVA indicated a significant treatment $\times$ day interaction effect
$(\mathrm{F}(12,140)=6.1, p<0.01)$ on motor activity after sodium benzoate infusions during induction. All rats treated with systemic cocaine and intra-VTA vehicle saline or sodium benzoate presented a significant enhancement of motor activity on days $5(p<0.05), 12$ and $20 v s$ day $1(p<0.01)$, but this effect was significantly higher on days 12 and 20 in those animals treated with sodium benzoate (100 and $200 \mu \mathrm{g} / \mu \mathrm{l}, p<0.05 v s$ vehicle on days 12 and 20 ), as shown in Figure 2. Thus, percentage increase in distance traveled on days 12 and 20 relative to day 1 was significantly higher in rats pretreated with sodium benzoate (day 12, $100 \mu \mathrm{g} / \mu \mathrm{l}, \quad 156.6 \pm 21 \% ; \quad 200 \mu \mathrm{g} / \mu \mathrm{l}, \quad 174.4 \pm 20 \%, \quad p<0.05$; day $20,100 \mu \mathrm{g} / \mu \mathrm{l}, 181.4 \pm 20 \% ; 200 \mu \mathrm{g} / \mu \mathrm{l}$, and $181.9 \pm 10 \%$, $p<0.05$ ) than vehicle (day 12, $99.5 \pm 9 \%$ and day 20, $99.2 \pm 10 \%)$. As for time-course study, ANOVA indicated a significant interaction effect $(\mathrm{F}(25,234)=72.2, p<0.01)$. Post hoc analysis revealed that distance traveled was enhanced from 0 to $60 \mathrm{~min}$ in all groups on day $20 v s$ day $1(p<0.01)$, and this value was significantly higher on day 20 in rats treated with 100 and $200 \mu \mathrm{g} / \mu \mathrm{l}$ sodium benzoate $v s$ vehicle-treated rats on the same day $(p<0.05)$ from 0 to $40 \mathrm{~min}$ post-injection. Hence, intra-VTA sodium benzoate, inhibitor of DAAO, was able to enhance cocaine's-sensitizing effects.
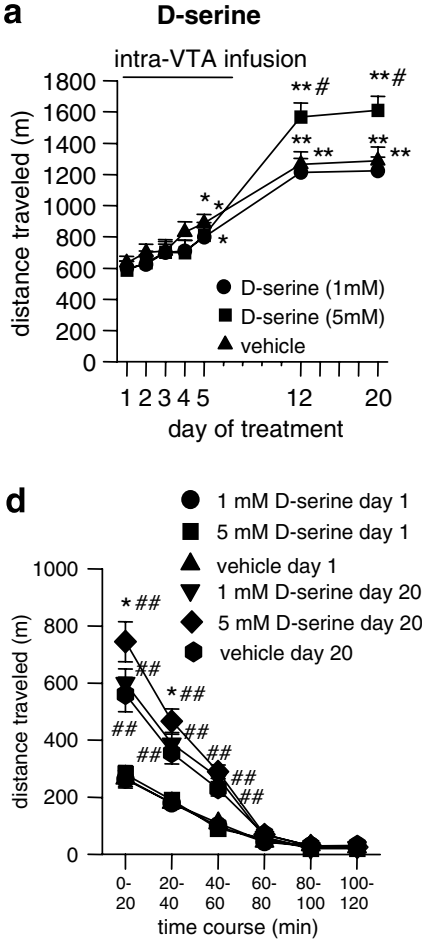
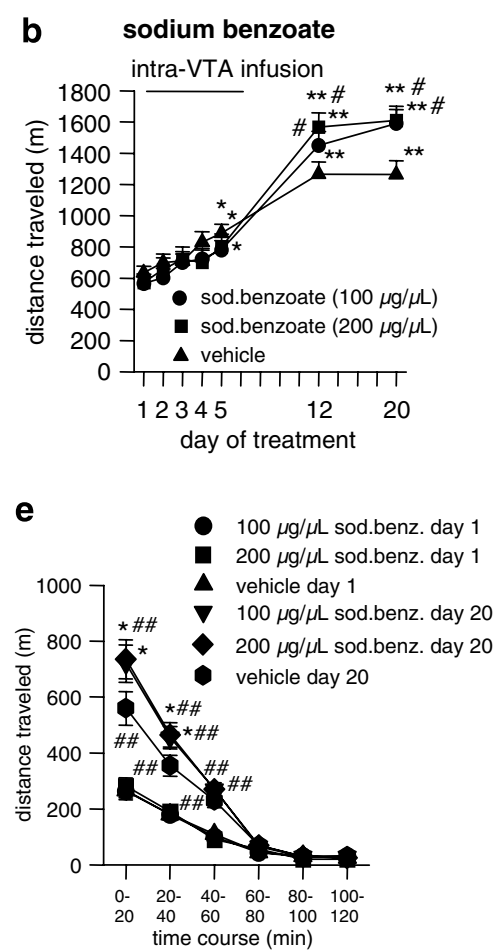
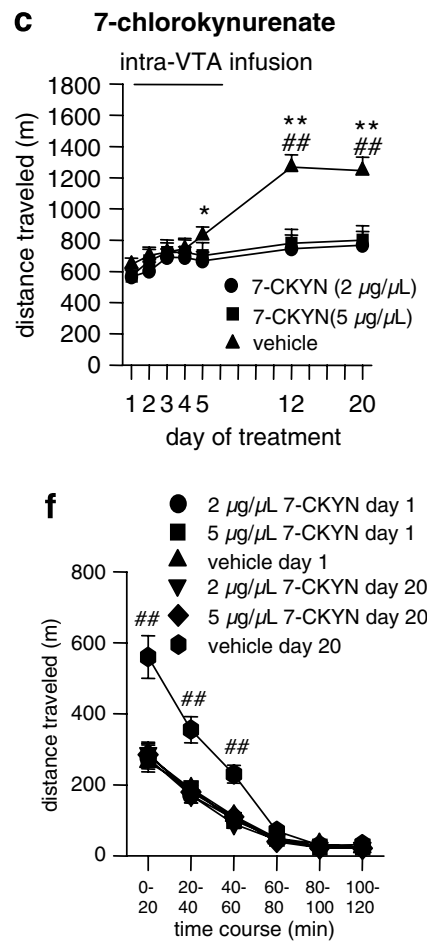

Figure 2 Sensitivity to motor activating effects of cocaine after intra-VTA infusions of D-serine (a, and d) sodium benzoate (b, and e), 7-chlorokynurenate $(c$, and $f$ ), and corresponding vehicle during the induction phase of sensitization (days I-5). Top row: (a, and b) All animals repeatedly treated with systemic cocaine and intra-VTA D-serine and sodium benzoate had heightened sensitivity to cocaine's-activating effects on days 5,12 , and 20 . However, rats treated with D-serine $(5 \mathrm{mM})$ and sodium benzoate (both doses) presented a higher locomotor effect than vehicle on days 12 and 20 . (c) Animals repeatedly treated with systemic cocaine and intra-VTA 7-chlorokynurenate (both doses) did not show locomotor sensitization on days 5, 12, or 20, in contrast to intra-VTA vehicle-treated rats. Data are expressed as mean \pm SEM, ${ }^{*} p<0.05,{ }^{*} * p<0.0$ I vs corresponding vehicle rats (Tukey's test); ${ }^{\#} p<0.05$, ${ }^{\# \#} p<0.0$ I vs distance traveled on day I by the same group (Student's t-test). Bottom row: time course of the distance ravelled following cocaine administration on days I and 20. ( $\mathrm{d}$ and e) Distance traveled was enhanced from 0 to $60 \mathrm{~min}$ in all groups on day $20 \mathrm{vs}$ day I $(p<0.0 \mathrm{I}$ ), and this value was significantly higher on day 20 in rats treated with (d) $5 \mathrm{mM}$ D-serine or (e) both doses of sodium benzoate ( 100 and $200 \mu \mathrm{g} / \mu \mathrm{l})$ vs the other groups at the same day from 0 to 40 min post-injection. ( $f$ ) Distance traveled was enhanced from 0 to $60 \mathrm{~min}$ in rats treated with intra-VTA vehicle on day 20 vs day I ( $p<0.0 \mathrm{I}$ ), but not in those animals treated with 2 and $5 \mu \mathrm{g} / \mu \mathrm{l} 7$-chlorokynurenate. Data are expressed as mean \pm SEM, $* p<0.05$ vs the other groups on day 20 ; $\# \#<0.01$ vs corresponding groups on day I (Student's t-test). Abbreviations: sod. benzoate, sodium benzoate; 7-CKYN, 7-chlorokynurenate. 
Repeated Intra-VTA Infusion of 7-Chlorokynurenate during the Induction Phase Blocks the Development of Sensitization to Cocaine

Two-way ANOVA indicated a significant treatment $\times$ day interaction $(\mathrm{F}(12,138)=3.6, p<0.05)$ effects on motor activity after infusions of 7-chlorokynurenate during induction. All rats treated with systemic cocaine and intra-VTA vehicle presented a significant enhancement of motor activity on days $5(p<0.05), 12$ and $20(p<0.01) v s$ day 1 , but this effect was absent in those animals treated with 7-chlorokynurenate ( 5 and $10 \mu \mathrm{g} / \mu \mathrm{l}$ ). Thus, percentage increase in distance traveled on days 12 and 20 relative to day 1 was significantly higher in rats pretreated with intraVTA vehicle (day $12,96.7 \pm 10 \%$; day $20,93.3 \pm 8 \%, p<0.01$ ) than 7 -chlorokynurenate $2 \mu \mathrm{g} / \mu \mathrm{l}$ (day $12,31.8 \pm 4 \%$ and day $20,35.7 \pm 5 \%$ ) and $5 \mu \mathrm{g} / \mu \mathrm{l}$ (day $12,36.6 \pm 6 \%$ and day $20,40.2 \pm 4 \%$ ) as shown in Figure 2. As for time-course study, ANOVA indicated a significant interaction effect $(\mathrm{F}(25,236)=32.2, p<0.05)$. Post hoc analysis revealed that distance traveled was enhanced from 0 to $60 \mathrm{~min}$ in rats treated with vehicle on day $20 v s$ day $1(p<0.01)$, but not in those animals treated with 2 and $5 \mu \mathrm{g} / \mu \mathrm{l}$ 7-chlorokynurenate. Hence intra-VTA 7-chlorokynurenate was able to block cocaine's sensitizing effects.

Effects of Intra-VTA Infusions of Sodium Benzoate, D-Serine and 7-Chlorokynurenate Alone on Locomotor Activity

Table 1 summarizes the control experiments designed to determine if sodium benzoate, D-serine and 7-chlorokynurenate elicited a behavioral effect of their own. The animals were pretreated with sodium benzoate, D-serine, and 7chlorokynurenate or corresponding vehicle before a systemic injection of saline rather than cocaine. No significant effects were revealed by two-way ANOVA.

Intra-VTA Infusion of D-Serine, Sodium Benzoate, or 7-Chlorokynurenate during the Expression Phase does not Alter the Emergence of Sensitization to Cocaine

Two-way ANOVA indicated a significant day effect after intra-VTA infusion of either D-serine $(F(6,138)=238$, $p<0.01)$, sodium benzoate $(\mathrm{F}(6,140)=234, p<0.01)$, or 7-chlorokynurenate $(\mathrm{F}(6,139)=234.3, p<0.01)$. Post hoc analyses revealed that every group treated with systemic cocaine presented a significant increase in locomotion on days $5(p<0.05), 12$ and $20 v s$ day $1(p<0.01)$, as shown in Figure 3. As for time course study, ANOVA indicated significant interaction effects (D-serine; $\mathrm{F}(25,240)=70.1$, $p<0.01$; sodium benzoate, $\mathrm{F}(25,236)=68.8, p<0.01$; and 7-chlorokynurenate, $\mathrm{F}(25,240)=67.7, p<0.01)$. Post hoc analysis revealed that distance traveled was enhanced from 0 to $60 \mathrm{~min}$ in all groups on day $20 v s$ day $1(p<0.01)$, without significant differences among groups at the same time point.

Repeated Cocaine Administration Activates CaMKII in the VTA, and Co-treatment with Intra-VTA D-Serine or Sodium Benzoate Further Activates CaMKII

The data presented in Figure 4 summarize the effects of acute saline, acute cocaine, repeated saline, or repeated cocaine (with intra-VTA $5 \mathrm{mM}$ D-serine, $200 \mu \mathrm{g} / \mu$ l sodium benzoate, $5 \mu \mathrm{g} / \mu \mathrm{l} 7$-chlorokynurenate, or vehicle) on VTA total protein levels of CaMKII and CaMKII(P), the activated form of CaMKII, 24 after a single injection or after the last of five daily injections. No significant differences between the groups treated with either acute saline or cocaine were revealed by the Student's $t$-test. In rats repeatedly treated with cocaine, one-way ANOVA revealed a significant treatment effect $(\mathrm{F}(4,35)=51.5, p<0.01)$. Post hoc analysis indicated that repeated cocaine (intra-VTA vehicle) induced a significant increase in the expression of CaMKII(P) in the VTA $v s$ repeated saline $(t=2.6, p<0.05)$, and this signal was reliably augmented after D-serine $5 \mathrm{mM}(t=2.3, p<0.05 v \mathrm{~s}$ intra-VTA vehicle, $t=3.3, p<0.01 v s$ control) and sodium benzoate $200 \mu \mathrm{g} / \mu \mathrm{l}(t=2.4, p<0.05 v s$ intra-VTA vehicle, $t=3.5, p<0.01$ vs control). Besides CaMKII(P) signal was significantly reduced after $5 \mu \mathrm{g} / \mu \mathrm{l}$ 7-chlorokynurenate $(p<0.01 v s$ the remainder groups). Total amount of CaMKII was not modified after intra-VTA D-serine, sodium benzoate, or 7-chlorokynurenate, as shown in Figure 4. Whether activation of CaMKII is revealed through a positive relation between its phosphorylated form and total CaMKII content, these data indicate that VTA CaMKII was activated after

Table I The Effect of Repeated Microinjections of D-Serine, Sodium Benzoate, and 7-Chlorokynurenate Directly into the VTA on Locomotor Activity

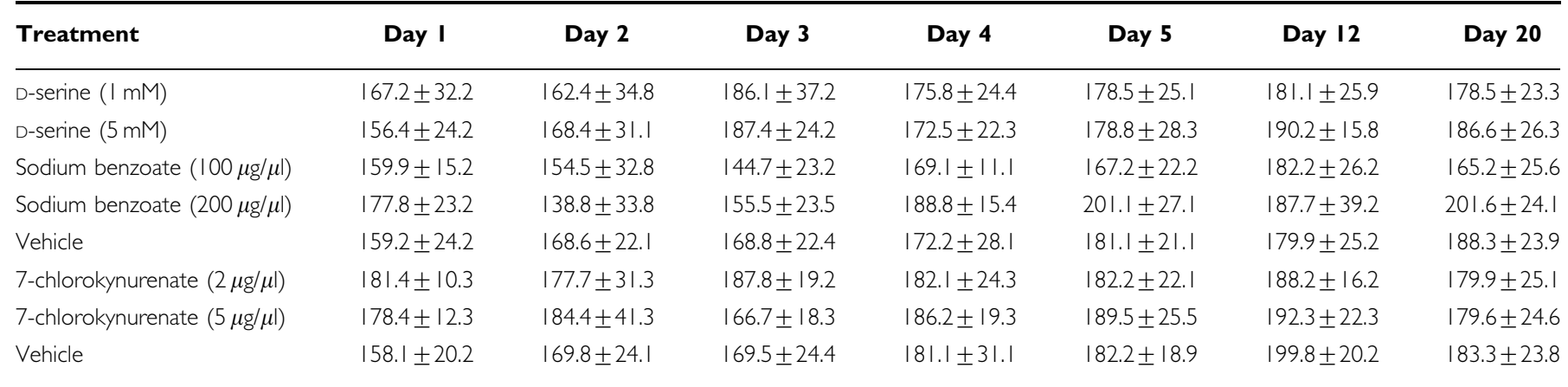

Mean \pm SEM of distance traveled in meters $(2 \mathrm{~h})$. On days $\mathrm{I}-5,12$ and 20 rats received intra-VTA microinfusions of sodium benzoate, its vehicle, D-serine, 7-chlorokynurenate or their vehicle into the VTA (after I h of habituation to the environment). Ten minutes later they received a systemic injection of saline and their behavior was monitored for $2 \mathrm{~h}$. 

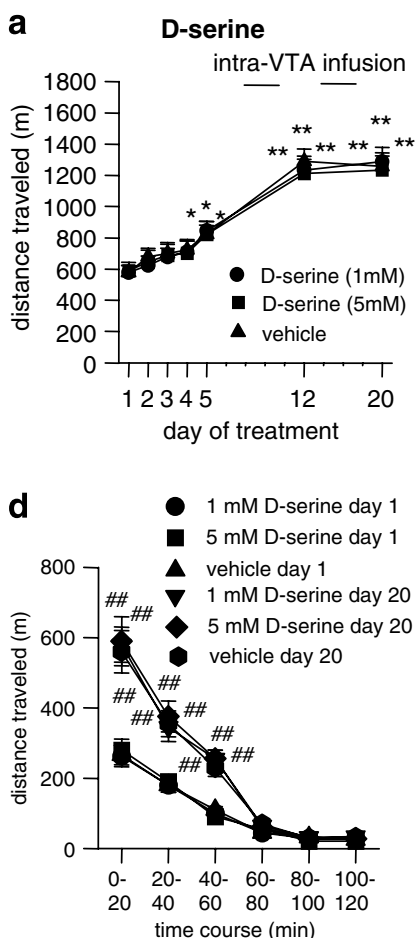

b
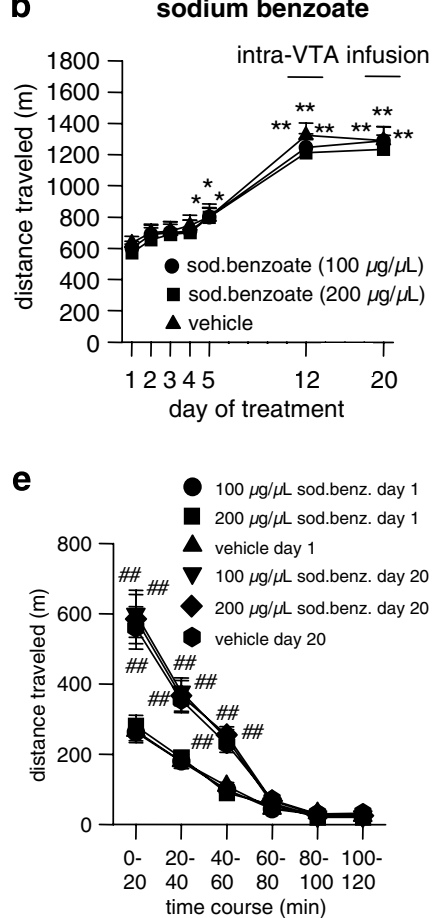

C 7-chlorokynurenate
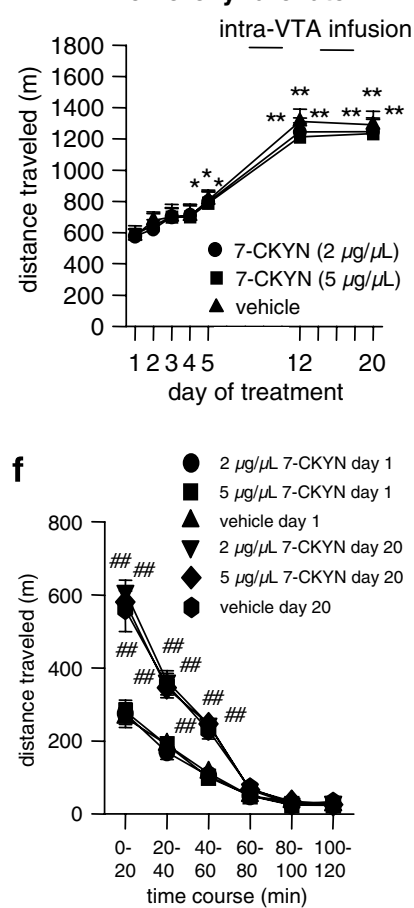

Figure 3 Sensitivity to motor-activating effects of cocaine after intra-VTA infusions of D-serine (a), sodium benzoate (b), 7-chlorokynurenate (c), and corresponding vehicle during the expression phase of sensitization (days 12 and 20). All animals treated with intra-VTA D-serine, sodium benzoate, 7 chlorokynurenate, and corresponding vehicle and repeatedly systemic cocaine had heightened sensitivity to cocaine's activating effects on days 5 , 12 , and 20. Data are expressed as mean \pm SEM, $* p<0.05$, ** $p<0.01$ vs distance traveled on day I by the same group (Tukey's test). Bottom row: time course of the distance ravelled following cocaine administration on days I and 20. (d-f) Distance traveled was enhanced from 0 to 60 min in all groups on day 20 vs day I $\left(p<0.0\right.$ I). Data are expressed as mean $\pm S E M,{ }^{\# \#} p<0.01$ vs corresponding groups on day I (Student's t-test). Abbreviations: sod. benzoate, sodium benzoate; 7-CKYN, 7-chlorokynurenate.
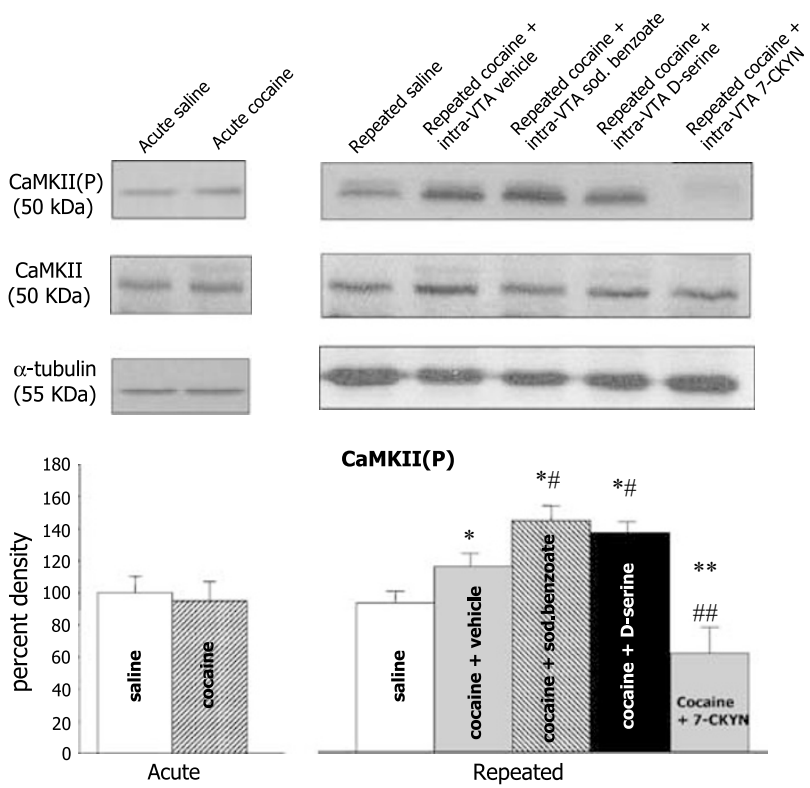

Figure 4 Representative immunoblot analysis of VTA CaMKII(P) and CaMKII in rats treated acutely or repeatedly with cocaine (preceded by intraVTA $5 \mathrm{mM}$ D-serine, $200 \mu \mathrm{g} / \mu$ l sodium benzoate, $5 \mu \mathrm{g} / \mu \mathrm{l}$ 7-chlorokynurenate or corresponding vehicle) and saline. $\alpha$-Tubulin was used as control protein. Bottom: mean percent density values of CaMKII(P) bands (saline group considered as 100\%). Data are expressed as mean \pm SEM, $* p<0.05$, ${ }^{*} * * 0.01$ vs corresponding saline-treated rats; ${ }^{\#} p<0.05$, ${ }^{\# \#} p<0.01$ vs cocaine-treated rats with intra-VTA vehicle (Student's t-test). Abbreviations: sod. benzoate, sodium benzoate; 7-CKYN, 7-chlorokynurenate.
intra-VTA infusions or D-serine and sodium benzoate, and state of activation was reduced after 7-chlorokynurenate.

\section{DISCUSSION}

The findings of the present study indicate that D-serine in the VTA participates in the induction (not expression) of motor sensitization to cocaine. Thus intra-VTA administration of exogenous D-serine and sodium benzoate reliably augmented the development of behavioral sensitization to cocaine. Sensitization effects were found to be long-lasting (challenge cocaine doses on days 12 and 20), a critical issue in behavioral sensitization. Besides motor sensitization was already observed in every group after 5 days of repeated cocaine, a finding in agreement with those reported by other authors after repeated cocaine in rats (Miserendino et al, 1993; Licata et al, 2004). This sensitization effect is otherwise in contrast with the fact that a challenging cocaine dose 1 day after withdrawal of repeated cocaine is known to induce an attenuation (not sensitization) of cocaine-induced locomotor response (Williams and Steketee, 2005), indicating that sensitivity to motor activating effects of cocaine are opposite if evaluated during the last day of repeated cocaine injections or 1 day after withdrawal.

The observed effects on sensitization after infusions of sodium benzoate reveal that endogenous $D$-serine is responsible of them, because sodium benzoate inhibits D-serine degradation leading to accumulation of $D$-serine 
in the VTA biophase, since it is a specific inhibitor of DAAO, the degradating enzyme of D-serine (Konno and Yasumura, 1992; Park et al, 2006). Astrocytes seem to participate on these effects, because these cells express DAAO and release D-serine (Yang et al, 2003; Park et al, 2006). However, a role for neurons in D-serine action cannot be discarded, because they synthesize and release D-serine as well, as reported recently by Kartvelishvily et al (2006). Dserine modulates NMDA receptor activity in the central nervous system (Schell et al, 1995; Haydon, 2001; Boehning and Snyder, 2003) and acts through binding to NMDA receptors at the glycine site, thereby facilitating their activation (Yang et al, 2003). In this context, sensitizationrelated changes in the VTA have been compared to LTP in the hippocampus, and astrocytes play a key role in longterm synaptic plasticity. Besides it is known that a single injection of cocaine can induce LTP of AMPA receptormediated current in dopaminergic neurons in the VTA (Ungless et al, 2001). Stimulation of NMDA receptors is needed for the development of cocaine's sensitization (Karler et al, 1991; Kalivas and Alesdatter, 1993; Licata et al, 2000; Licata and Pierce, 2003), and confirming the important role of NMDA receptors and their activation at the glycine site, the employment of 7-chlorokynurenate, a specific antagonist of the glycine site of NMDA receptors, led to blocking of the initiation of sensitization to cocaine. This is in line with other reports demonstrating that the use of antagonist for the glycine/NMDA receptor such as $\mathrm{R}-(+$ )-HA-966 are able to prevent locomotor sensitization to repeated cocaine (Morrow et al, 1995). The NMDA receptor consists of several distinct binding sites identified by the ligand: glutamate or NMDA, PCP, or MK-801, glycine, as well as $\mathrm{Mg}^{2+}$-binding site. D-Serine and glycine are coagonists with glutamate for the NMDA receptor ionophore (Huettner, 1991), and the present study reveals that this coagonism in the VTA is needed for the initiation of locomotor sensitization to cocaine.

The findings indicated that the glycine site in NMDA receptors seems not to be saturated by $\mathrm{D}$-serine under physiological conditions because of the facilitation of behavioral sensitization by the higher dose of D-serine, a fact otherwise in accordance with Fuchs et al (2005), who demonstrated that in vivo the NMDA glycine site is not saturated in all brain regions. This fact leads us to hypothesize that a dysfunction of $\mathrm{D}$-serine metabolism, for instance in DAAO activity, could underlie vulnerability to chronic effects of cocaine because NMDA receptors and hence cocaine's sensitization will be further stimulated. In this context, several authors present evidence that variations in the G72 or DAOA gene region increase risk for psychosis in humans (Chumakov et al, 2002; Goldberg et al, 2006). The gene product of DAOA is an activator of DAAO gene, and variations in the DAOA gene are known to induce indirect effects on NMDA neurotransmission (Chumakov et al, 2002; Goldberg et al, 2006). It is worth noting that individual vulnerability to cocaine's sensitization is also associated to a higher risk to cocaine-induced psychosis (Satel et al, 1991; Brady et al, 1991; Bartlett et al, 1997), pointing to a possible relationship between DAAO activity and sensitization. Recently, it has been reported that knockout mice that lack DAAO activity present enhanced NMDAR function together with increased occupancy of the
NMDAR glycine site due to elevated extracellular D-serine levels (Almond et al, 2006). This latter fact otherwise supports that NMDA receptors are not saturated by D-serine under physiological conditions in rodents (Fuchs et al, 2005).

\section{Calcium and CaMKII Signaling and Sensitization}

Enhanced levels of calcium in the VTA mediates the locomotor activating effects of cocaine (Pierce et al, 1996; Licata and Pierce, 2003). Mechanisms underlying this effect are not clear, but glutamatergic AMPA and NMDA receptors along with L-type calcium channels are involved, because they become more permeable to calcium after cocaine's administration (Licata and Pierce, 2003). Following increase in intracellular calcium, this ion binds calmodulin (calcium/CaM complex) and then calciumdependent kinases such as CaMKII bind calcium/CaM become phosphorylated and activated by CaMKK. It is well known that cocaine injections enhance total CaMKII protein in the VTA (Licata et al, 2004), and the present study provides evidence that CaMKII is activated after repeated cocaine, and D-serine acts positively in this process likely as a co-factor for activation of NMDA receptors. Furthermore, it was observed that 7-chlorokynurenate has a strong inhibiting effects on the formation of CaMKII(P) by itself, as revealed through blotting. This finding is quite interesting because this $\operatorname{CaMKII}(\mathrm{P})$ downregulation was not accompanied by acute locomotor response to cocaine. Recently, it has been reported that suppressing CaMKII activity in the VTA enhances the acute response to $15 \mathrm{mg} / \mathrm{kg}$ cocaine and attenuates the initiation of cocaine-induced behavioral sensitization in rats (Licata et al, 2004). Our findings support this latter effect, but acute hyper locomotion was not observed likely because CaMKII activity was not fully inhibited, and a reduction of around $50 \%$ in its activity would not be sufficient to enhance acute motor activating effects of $10 \mathrm{mg} / \mathrm{kg}$ cocaine. In accordance, Licata et al (2004) report that a high intra-VTA dose of the CaMKII inhibitor KN-93 (6 $\mu \mathrm{g}$ in a volume of $1 \mu \mathrm{l})$ but not a lower one $(0.6 \mu \mathrm{g}$ in a volume of $1 \mu \mathrm{l})$ is able to enhance the acute motor response to cocaine.

CaMKII is a transducer of calcium signaling, this kinase being expressed in many brain regions (Sola et al, 1999; Nakamura et al, 2000), including the VTA (Licata et al, 2004). Calcium signaling pathways play a pivotal role in synaptic plasticity and memory formation (Dubnau and Tully, 1998; Ho et al, 2000), as well as CaMKII (Silva et al, 1992). CaMKII functions as a potent stimulator of calcium-dependent gene expression, and it activates several transcription factors such as CREB, which is phosphorylated on the regulatory Ser133 residue (Matthews et al, 1994; Curtis and Finkbeiner, 1999). CREB activation in the VTA is directly involved in sensitization and regulates tyrosine hydroxylase (TH) transcription (Lim et al, 2000). TH immunoreactivity and enzymatic activity are increased in rats repeatedly treated with cocaine (Beitner-Johnson and Nestler, 1991; Sorg et al, 1993; Vrana et al, 1993), leading to enhanced dopamine synthesis in the VTA. Enhancement of dopamine release in the VTA is a key fact underlying the development of sensitization to cocaine (Parsons and Justice, 1993; Kalivas and Duffy, 1998; Licata and Pierce, 2003). Calcium influx and 
CaMKII have also been implicated in the production and responsiveness to neurotrophic factors such as BDNF (Finkbeiner et al, 1997; Tao et al, 1998). Interestingly, BDNF participates on cocaine's sensitization because direct infusion of BDNF into the VTA blocks the ability of cocaine to produce some biochemical and morphological effects in this region, such as the induction of $\mathrm{TH}$ (Berhow et al, 1995, 1996). In conclusion, the findings are consistent with the hypothesis that CaMKII in the VTA plays an important role in the initiation (not expression) of cocaine's sensitization, likely through activation of several transcription factors and proteins involved in the emergence of sensitization (Licata et al, 2004). The findings confirm the proposal by Licata and Pierce (2003) that calcium-stimulated second messengers may be the crucial link between the development and longterm expression of behavioral sensitization to cocaine, and $\mathrm{D}$-serine is involved in their activation after repeated cocaine.

\section{CONCLUSIONS}

The findings of the present study provide evidence that D-serine in the VTA participates in the induction (not expression) of cocaine's sensitization. Thus intra-VTA administration of D-serine (agonist of the glycine site of NMDA receptors) and sodium benzoate (inhibitor of DAAO, the degradating enzyme of D-serine) reliably augmented the expression of behavioral sensitization to cocaine. Confirming the important role of NMDA receptors and their activation at the glycine site, the employment of 7 chlorokynurenate (inhibitor of the glycine site of NMDA receptors) led to blocking of the development of sensitization to cocaine. Intra-VTA infusions of $\mathrm{D}$-serine, sodium benzoate and 7-chlorokynurenate did not elicit a motor effect of their own. Finally, CaMKII within the VTA was found to participate in D-serine's effects because this kinase, that is activated after repeated cocaine, was further activated after co-treatment with D-serine or sodium benzoate, and CaMKII activity was otherwise reduced by 7-chlorokynurenate.

\section{ACKNOWLEDGEMENTS}

Supported by grants to EFE from Spanish FIS (PI040155), Plan Andaluz de Investigacion (CVI127), RED de trastornos adictivos (Instituto Carlos III, RD06/0001), and Delegacion del Gobierno para el Plan Nacional sobre Drogas (3SI/05/14).

\section{DISCLOSURE/CONFLICT OF INTEREST}

The author(s) declare that, except for income received from their primary employer, no financial support or compensation has been received from any individual or corporate entity over the past 3 years for research or professional service and there are no personal financial holdings that could be perceived as constituting a potential conflict of interest.

\section{REFERENCES}

Almond SL, Fradley RL, Armstrong EJ, Heavens RB, Ruttr AR, Newman RJ et al (2006). Behavioral and biochemical chracterization of a mutant mouse strain lacking D-amino acid oxidase activity and its implications for schizophrenia. Mol Cell Neurosci 32: 324-344.

Bartlett E, Hallin A, Chapman B, Angrist B (1997). Selective sensitization to the psychosis-inducing effects of cocaine: a possible marker for addiction relapse vulnerability? Neuropsychopharmacology 16: 77-82.

Beitner-Johnson D, Nestler EJ (1991). Morphine and cocaine exert common chronic actions on tyrosine hydroxylase in dopamine brain reward regions. J Neurochem 57: 344-347.

Berhow MT, Hiroi N, Nestler EJ (1996). Regulation of ERK (extracellular signal regulated kinase), part of the neurotrophin signal transduction cascade, in the rat mesolimbic dopamine system by chronic exposure to morphine or cocaine. J Neurosci 16: 4707-4715.

Berhow MT, Russell DS, Terwilliger RZ, Beitner-Johnson D, Self DW, Lindsay RM et al (1995). Influence of neurotrophic factors on morphine- and cocaine-induced biochemical changes in the mesolimbic dopamine system. Neuroscience 68: 969-979.

Boehning D, Snyder SH (2003). Novel neural modulators. Annu Rev Neurosci 26: 105-131.

Brady KT, Lydiard B, Malcolm R, Ballinger JC (1991). Cocaineinduced psychosis. J Clin Psychiatry 52: 509-512.

Chumakov I, Blumenfeld M, Guerassimenko O, Cavarec L, Palicio $\mathrm{M}$, Abderrahim $\mathrm{H}$ et al (2002). Genetic and physiological data implicating the new human gene G72 and the gene for D-amino acid oxidase in schizophrenia. Proc Natl Acad Sci USA 99: 13675-13680.

Curtis J, Finkbeiner S (1999). Sending signals from the synapse to the nucleus: possible roles for CaMK, Ras/ERK, and SAPK pathways in the regulation of synaptic palsticity and neuronal growth. J Neurosci Res 58: 88-95.

Dubnau J, Tully T (1998). Gene discovery in Drosophila: new insights for learning and memory. Annu Rev Neurosci 21: 407-444.

Finkbeiner S, Tavazoie SF, Maloratsky A, Jacobs KM, Harris KM, Greenberg ME (1997). CREB: a major mediator of neuronal neurotrophin responses. Neuron 19: 1031-1047.

Fuchs SA, Berger R, Klomp LW, de Koning TJ (2005). D-amino acids in the central nervous system in health and disease. Mol Genet Metab 85: 168-180.

Goldberg TE, Straub RE, Callicott JH, Hariri A, Mattay VS, Bigelow $\mathrm{L}$ et al (2006). The G72/G30 gene complex and cognitive abnormalities in schizophrenia. Neuropsychopharmacology 31: 2022-2032.

Haydon PG (2001). GLIA: listening and talking to the synapse. Nat Rev Neurosci 2: 185-193.

Ho N, Liauw JA, Blaeser F, Wei F, Hanissian S, Muglia LM et al (2000). Impaired synaptic plasticity and cAMP response element-binding protein activation in $\mathrm{Ca} 2+/$ calmodulin-dependent protein kinase type IV/Gr-deficient mice. J Neurosci 20: 6459-6472.

Huettner JE (1991). Competitive antagonism of glycine at the $\mathrm{N}$-methyl-D-aspartate (NMDA) receptor. Biochem Pharmacol 41: 9-16.

Kalivas PW, Alesdatter JE (1993). Involvement of NMDA receptor stimulation in the VTA and amygdala in behavioral sensitization to cocaine. J Pharmacol Exp Ther 267: 486-495.

Kalivas PW, Duffy P (1998). Repeated cocaine administration alters extracellular glutamate in the ventral tegmental area. J Neurochem 70: 1497-1502.

Karler R, Turkanis SA, Partlow LM, Calder LD (1991). Calcium channel blockers in behavioral sensitization. Life Sci 49: 165-170.

Kartvelishvily E, Shleper M, Balan L, Dumin E, Wolosker H (2006). Neuron-derived D-serine release provides a novel means to activate $N$-methyl-D-aspartate receptors. J Biol Chem 281: 14151-14162.

Kelley AE (2004). Memory and addiction: shared neural circuitry and molecular mechanisms. Neuron 44: 161-179. 
Konno R, Yasumura Y (1992). D-amino-acid oxidase and its physiological function. Int J Biochem 24: 519-524.

Koob GF, Bloom FE (1988). Cellular and molecular mechanisms of drug dependence. Science 242: 715-723.

Licata SC, Freeman AY, Pierce-Bancroft AF, Pierce RC (2000). Repeated stimulation of L-type calcium channels in the rat ventral tegmental area mimics the initiation of behavioral sensitization to cocaine. Psychopharmacology 152: 110-118.

Licata SC, Pierce RC (2003). The roles of calcium/calmodulindependent and Ras/mitogen-activated protein kinases in the development of psychostimulant-induced behavioral sensitization. J Neurochem 85: 14-22.

Licata SC, Schmidt HD, Pierce RC (2004). Suppressing calcium/ calmodulin-dependent protein kinase II activity in the ventral tegmental area enhances the acute behavioural response to cocaine but attenuates the initiation of cocaine-induced behavioural sensitization in rats. Eur J Neurosci 19: 405-414.

Lim J, Yang C, Hong SJ, Kim KS (2000). Regulation of tyrosine hydroxylase gene transcription by the cAMP-signaling pathway: involvement of multiple transcription factors. Mol Cell Biochem 212: $51-60$.

Matthews RP, Guthrie CR, Wailes LM, Zhao X, Means AR, Mcknight GS (1994). Calcium/calmodulin-dependent protein kinases types II and IV differentially regulate CREB-dependent gene expression. Mol Cell Biol 14: 6017-6116.

Miserendino MJD, Guitart X, Terwilliger RZ, Chi S, Nestler EJ (1993). Individual differences in locomotor activity are associated with levels of tyrosine hydroxylase and neurofilament proteins in the ventral tegmental area of Sprague-Dawley rats. Mol Cell Neurosci 4: 440-448.

Morrow BA, Taylor JR, Roth HR (1995). R-(+)-HA-966, an antagonist for the glycine/NMDA receptor, prevents locomotor sensitization to repeated cocaine exposures. Brain Res 673: 165-169.

Nakamura Y, Kitani T, Okuno S, Otake K, Sato F, Fujisawa H (2000). Immunohistochemical study of the distribution of $\mathrm{Ca}(2+) /$ calmodulin-dependent protein kinase phosphatase in the rat central nervous system. Brain Res Mol Brain Res 77: 76-94.

Nestler EJ (2001). Molecular basis of long-term plasticity underlying addiction. Nat Rev Neurosci 2: 119-128.

Park K, Shishido Y, Ichise-Shishido S, Kawazoe T, Ono K, Iwana S et al (2006). Potential role for astroglial D-amino acid oxidase in extracellular D-serine metabolism and cytotoxicity. $J$ Biochem (Tokyo) 139: 295-304.

Parsons LH, Justice JB (1993). Serotonin and dopamine sensitization in the nucleus accumbens, ventral tegmental area and dorsal raphe nucleus following repeated cocaine administration. J Neurochem 61: 1611-1619.

Paxinos G, Watson C (2005). The Rat Brain in Stereotaxic Coordinates. Elsevier Academic Press: Amsterdam.
Pierce RC, Born B, Adams M, Kalivas PW (1996). Repeated intraventral tegmental area administration of SKF-38393 induces behavioral and neurochemical sensitization to a subsequent cocaine challenge. J Pharmacol Exp Ther 278: 384-392.

Reimer AR, Martin-Iverson MT (1994). Nimodipine and haloperidol attenuate behavioral sensitization to cocaine but only nimodipine blocks the establishment of conditioned locomotion induced by cocaine. Psychopharmacology 113: 404-410.

Robinson TE, Berridge KC (1993). The neural basis of drug craving: an incentive-sensitization theory of addiction. Brain Res Rev 18: 247-291.

Satel SL, Southwick SM, Gawin FH (1991). Clinical features of cocaine-induced paranoia. Am J Psychiatry 1248: 495-498.

Schell MJ, Brady Jr RO, Molliver ME, Snyder SH (1997). D-serine as a neuromodulator: regional and developmental localizations in rat brain glia resemble NMDA receptors. J Neurosci 17: $1604-1615$

Schell MJ, Molliver ME, Snyder SH (1995). D-serine, an endogenous synaptic modulator: localization to astrocytes and glutamatestimulated release. Proc Natl Acad Sci USA 92: 3948-3952.

Silva AJ, Paylor R, Wehner JM, Tonegawa S (1992). Impaired spatial learning in alpha-calcium-calmodulin kinase II mutant mice. Science 257: 206-211.

Sola C, Tusell JM, Serratosa J (1999). Comparative study of the distribution of calmodulin kinase II and calcineurin in the mouse brain. J Neurosci Res 57: 651-662.

Sorg BA, Chen SY, Kalivas PW (1993). Time course of tyrosine hydroxylase expression after behavioral sensitization to cocaine. J Pharmacol Exp Ther 266: 424-430.

Tao X, Finkbeiner S, Arnold DB, Shaywitz AJ, Greenberg ME (1998). Ca2+ influx regulates BDNF transcription by a CREB family transcription factor-dependent mechanism. Neuron 20: 709-726.

Ungless MA, Whistler JL, Malenka RC, Bonci A (2001). Single cocaine exposure in vivo induces long-term potentiation in dopamine neurons. Nature 411: 583-587.

Vrana SL, Vrana KE, Koves TR, Smith JE, Dworkin SI (1993). Chronic cocaine administration increases CNS tyrosine hydroxylase enzyme activity and mRNA levels and tryptophan hydroxylase enzyme activity levels. J Neurochem 61: 2262-2268.

Williams JM, Steketee JD (2005). Time-dependent effects of repeated cocaine administration on dopamine transmission in the medial prefrontal cortex. Neuropharmacology 48: 51-61.

Wise RA (2000). Addiction becomes a brain disease. Neuron 26: 27-33.

Wise RA, Rompre PP (1989). Brain dopamine and reward. Annu Rev Psychol 40: 191-225.

Yang Y, Ge W, Chen Y, Zhang Z, Shen W, Wu C et al (2003). Contribution of astrocytes to hippocampal long-term potentiation through release of D-serine. Proc Natl Acad Sci USA 100: 15194-15199. 